
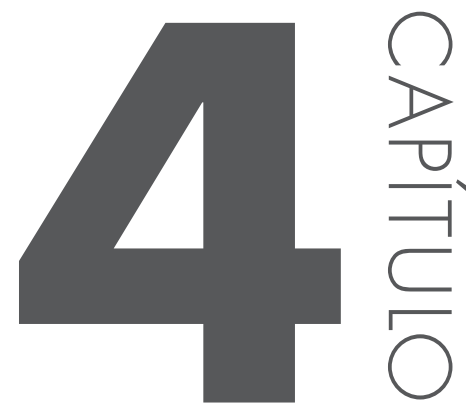

\title{
O VOTO FRENTE À REFORMA POLÍTICA: PROPOSTAS PARTIDÁRIAS PARA UM NOVO CENÁRIO ELEITORAL BRASILEIRO
}

de Castro, Leonardo Aires ${ }^{1 *}$; Abreu, Jonas Modesto ${ }^{2}$

' Graduando em Ciências Sociais pela Universidade Federal de Goiás. Bolsista de Iniciação Cientifica PIBIC UFG/CNPq. Artigo revisado pelo orientador do projeto, Professor Dr. Jonas Modesto de Abreu

2 Professor de Ciência Políitica da Universidade Federal de Goiás. Orientador e coautor do artigo

*email: leoaires@outlook.com

\section{RESUMO}

As eleições de 2014 foram pautadas em propostas que fugiam do desiderato comum da população até as jornadas de junho de 2013, propostas essas encabeçadas por uma vontade de reformar não apenas alguns pontos do modelo político, mas todo ele. Em função de levar os anseios e conflitos da sociedade civil para todos os níveis das instituições políticas de poder do Estado, o partido político se converte em instituição indispensável para o exercício da democracia representativa. No cenário em que partidos surgem e desaparecem a cada eleição, encontram-se tanto partidos históricos, solidificados ideológica e programaticamente, quanto 
às comentadas legendas de aluguel que favorecem as negociatas e mazelas que vulgarizam o jogo de poder e a identidade partidária. Atualmente, a reforma do sistema político brasileiro é um dos temas mais debatidos nos meios políticos intelectualizados e, em diversos seguimentos organizados de nossa sociedade. Os partidos políticos são instituições centrais no decurso de uma reforma política que, aparentemente, tornou-se inevitável. Logo, as regras eleitorais devem se modificar com esse novo paradigma político, como por exemplo a instituição máxima e soberana da expressão popular, o voto. A discussão dos modelos eleitorais é o objetivo desse trabalho, não almejando estabelecer uma forma "perfeita" nas diversas estudadas. Embasando na produção bibliográfica nacional sobre o assunto, discutindo pontos favoráveis e negativos, este artigo analisará as propostas de reforma do sistema do voto no Brasil tendo como referência os partidos políticos mais relevantes no nosso atual jogo de tomada de decisões.

Palavras-chave: Reforma Política; Partidos Políticos; Voto.

Revisado pelo Orientador Jonas Modesto Abreu, contato: abreujm9@yahoo.com.br

de Castro, Leonardo Aires; Abreu, Jonas Modesto; "O VOTO FRENTE À REFORMA POLÍTICA: PROPOSTAS PARTIDÁRIAS PARA UM NOVO CENÁRIO ELEITORAL BRASILEI", p. 61-78 . In: Seminário de Pesquisa, Pós-Graduação e Inovação da Regional Catalão (2. : 2014 : Goiás) Coletânea Interdisciplinar em Pesquisa, Pós-Graduação e Inovação - Volume 2 : Humanidades e Letras. Anais [livro eletrônico] / organizado por Adriana Freitas Neves, Idelvone Mendes Ferreira, Maria Helena de Paula, Petrus Henrique Ribeiro dos Anjos. São Paulo: Blucher, 2015. ISBN: 978-85-8039-111-4, DOI 10.5151/9788580391114-V2_Cap4 


\section{INTRODUC̣ÃO}

A reforma política bate à porta do Congresso Nacional e urge na sociedade como um todo. Nas eleições de 2014, candidatos a deputado federal, senador e presidência se desdobraram para apresentar à sociedade um conjunto de propostas que podem conduzir o Brasil para um novo estágio do nosso processo democrático. Independente do campo ideológico e programático que diferencia os partidos políticos; hoje, amplos segmentos da classe política nacional entendem a necessidade de se promover mudanças nas regras do jogo eleitoral, buscando mais transparência nas ações políticas e nos mecanismos de combate à corrupção.

Nessa perspectiva, os partidos políticos brasileiros buscam sedimentar, tanto na sociedade, quanto entre os agentes e agremiações do universo político, a coalizão imprescindível para a realização da reforma política; cabendo ao executivo federal o papel de conduzir as negociações e ponderar, em conjunto com o Congresso Nacional, no processo de construção das novas regras que irão estabelecer a forma de se conduzir a política de nosso país nos próximos anos. Indícios deste processo que está em curso pôde ser visualizado durante a propaganda eleitoral de candidatos que concorriam à distintos cargos nestas eleições de 2014.

Inserido neste contexto, o partido político desempenha papel essencialmente relevante, pois ele espelha os interesses de seus membros, os candidatos. É no âmago da estrutura partidária que os candidatos - em regra - desenvolvem as suas propostas para a reforma do sistema político nacional e, em função disso, é do interesse deste trabalho apresentar os programas partidários e, a partir deles, compreender como vem sendo tratado o tema VOTO, até o momento, o mais mencionado, centro das discussões sobre a reforma política brasileira. Isso envolve uma discussão direcionada à ações que objetivam aprimorar o agir político, ampliar a representatividade do cidadão comum e diminuir as mazelas institucionais que degradam a imagem da democracia de nosso país.

O voto é o instrumento mais valioso e representativo da vontade popular. A existência do voto é indispensável para assegurar a manifestação da vontade social e, em decorrência disso, ele se constitui em pilar central dos regimes políticos assentados no Estado Democrático de Direito. Garantido pela Constituição de 1988 de maneira secreta e obrigatória, após os 18 anos, sendo opcional entre os cidadãos de 16 e 17 e maiores de 70 anos, o voto universal no Brasil espelha o contexto de demandas democráticas do momento da redemocratização brasileira que se dá após um regime autoritário comandado por militares que durou mais de duas décadas, sendo a essência do voto a construção de um 
sistema político justo e coerente. Passados 26 anos deste momento de clamor democrático inicial, observa-se uma nova demanda por mudanças nas regras do jogo político que, ao longo dos anos, já vêm sofrendo mudanças pontuais, ajustes e remendos que aparentemente têm sido insuficientes para sanar o desgaste ou saturação do modelo original.

Assim, intentando corrigir os erros do passado e aperfeiçoar o nosso modelo de voto, tornando-o exemplar, como ocorre com o modelo nacional de voto em urnas eletrônicas, a reformulação do sistema de exercício do voto no Brasil se tornou imprescindível para o aprimoramento da atual maquina eleitoral brasileira. Para seguir nesta direção, este artigo dispõe sobre propostas partidárias que intentam a modificação da estrutura do voto, no sentido mais amplo, orientando-se por autores que atualmente ganharam prestígio de referência nacional, Cícero Araújo, Cristian Klein, Fernando Limongi, Jairo Nicolau, Leonardo Avritzer, Maria Victoria Benevides e Renato Janine Ribeiro.

\section{O FOCO DE ANÁLISE}

Para dar sentido eficiente e relevante à pesquisa, apenas serão analisados os partidos políticos que têm representatividade no legislativo federal e que concorreram com candidaturas próprias às eleições presidências de 2014: Partido dos Trabalhadores (PT), Partido da Social Democracia Brasileira (PSDB), Partido Socialismo e Liberdade (PSoL), Partido Verde (PV), Partido Social Cristão (PSC) e Partido Socialista Brasileiro (PSB). De toda forma, sempre que necessário, também serão mencionadas as proposições relevantes advindas de partidos políticos expressivos que se apresentaram apenas coligados, sem candidatura presidencial própria, nesta eleição.

O Brasil adota os sistemas majoritário e proporcional de votos. Presidente da República, governadores de estado e do Distrito Federal, prefeitos e senadores, são cargos decorrentes de eleições majoritárias. Deputados Federais, deputados estaduais e distritais e vereadores são extraídos de pleitos proporcionais. $\mathrm{O}$ sistema majoritário, em um ou dois turnos, e o sistema proporcional de lista aberta, rendem diversas discussões no contexto geral dos debates sobre a reforma política brasileira. O mesmo se verifica nas discussões no Congresso Nacional. De forma genérica, é possível afirmar que todos os partidos analisados possuem uma proposta específica de modificação das regras eleitorais e, nela, identificamos as suas raízes programáticas ou ideológicas. 


\subsection{AS PROPOSTAS DOS PARTIDOS}

Dá para afirmar com segurança que são poucos os partidos que neste momento preestabeleceram diretrizes concretas sobre as reformas que pretendem levar a cabo caso componham bancadas no próximo quadriênio legislativo ou na Constituinte, exclusiva ou não. Nesta altura dos acontecimentos já há algumas sinalizações genéricas do rumo dos interesses partidários em consequência das posições ocupadas no jogo de poder que envolve a tomada de decisões e das condutas programáticas e ideológicas de cada partido. Contudo, conforme salienta Nicolau (2003), também não se pode deixar de notar que há uma preocupante generalização e um limitado aprofundamento no que tange a questão programática e de aplicabilidade das propostas em discussão, situação preocupante quando se sabe que se trata de um tema que vem sendo discutido no âmbito partidário pelo menos desde 1990 .

Em função do papel de centralidade que vem ocupando no cenário político nacional, a análise enfoca inicialmente o Partido dos Trabalhadores, que atualmente mantêm uma página eletrônica na qual busca cumprir a dupla função de, ao mesmo tempo, estimular a participação dos cidadãos no processo de reforma do sistema político brasileiro e, seguindo pela mesma direção, coletar assinaturas em quantidade suficiente para dar caráter de legitimidade, via pressão popular, ao intento de promover a reforma. No que diz respeito à estrutura do voto, o PT propõe a mudança da lista aberta para uma lista pré-ordenada, visando fortalecer os partidos políticos. Sendo assim, se deixaria de votar em um candidato, no personagem político, direcionando o voto para o partido político e suas diretrizes programáticas ou ideológicas. Caberia ao partido disponibilizar os nomes em uma lista ordenada, da qual reriam retirados para ocupar as cadeiras legislativas conquistadas eleitoralmente os integrantes ordenados segundo a conveniência dos partidos. Os partidos políticos e não o número de votos concedido ao candidato definiram os elementos prioritários para representar a legenda partidária nos nossos três níveis de parlamento.

Em consonância com a proposta do Partido dos Trabalhadores, o PSoL também defende o voto em lista pré-ordenada. O mesmo acorre com o Democratas (DEM). No entendimento do Partido da Social Democrata Brasileira, a votação em lista pré-ordenada se mostra positiva para a democracia, mas há a ressalva de se deixar o eleitor escolher a personalidade que o agrade, propondo um sistema distrital misto, no qual as unidades federativas seriam divididas em distritos eleitorais nos quais a ordem dos integrantes da lista partidária seria estabelecida pelo sistema eleitoral majoritário. Tal qual o PSDB, o Partido Popular Socialista (PPS) também propõe o modelo distrital misto de voto. 
Próximo desta proposta, o Partido do Movimento Democrático Brasileiro (PMDB) defende um modelo mais centralizador, chamado de "distritão". Neste caso, ao invés de se dividir as unidade federativas em vários distritos, seria formado um único distrito e os integrantes prioritários da lista também seriam definidos pelo sistema eleitoral majoritário. O Partido Social Cristão (PSC) também se associa a este modelo.

Em 2011 o Partido Socialista Brasileiro (PSB) manifestou posição em favor de se manter a atual estrutura eleitoral do voto, apesar disso e das particularidades que apartam a candidata presidencial de 2014 da legenda do partido, o programa de governo de Marina Silva destacou a necessidade de se por fim às eleições proporcionais no Brasil, concedendo as cadeiras legislativas a quem de fato conquistasse os votos necessários para ocupá-las, apontando, desta forma, para uma eleição majoritária que definisse os nomes dos legítimos ocupantes. Todavia, no programa presidencial de governo de Mariana Silva, concorrente pelo PSB, não há nenhuma menção a modelos centrados em distritos ou em listas pré-ordenadas.

Entre os partidos que apresentaram candidatura própria às eleições presidenciais deste ano, o Partido Verde (PV) é o único que não apresentou indicativos claros a respeito de uma reforma no sistema político e eleitoral de país, isso impede o seu enfoque nas discussões em voga.

\section{Quadro 1}

\begin{tabular}{cc}
\hline PARTIDOS POLÍTICOS & PROPOSTAS SOBRE O VOTO \\
\hline PT & VOTO EM LISTA PRÉ-ORDENADA \\
\hline PSDB & VOTO DISTRITAL MISTO \\
\hline PMDB & DISTRITÃO \\
\hline PSB & VOTO MAJORITÁRIO \\
\hline PSOL & VOTO EM LISTA PRÉ-ORDENADA \\
\hline DEM & VOTO EM LISTA PRÉ-ORDENADA \\
\hline PSC & DISTRIT̃̃OO \\
\hline PPS & VOTO DISTRITAL MISTO
\end{tabular}

Fonte: site oficial dos partidos. 


\subsubsection{O PROBLEMA NA ÓTICA DOS ESPECIALISTAS}

É relevante iniciar esta parte do trabalho descrevendo o atual panorama das regras eleitorais brasileiras. O sistema de voto adotado pelo Brasil para se eleger deputados e vereadores é proporcional e definido por uma lista aberta. Neste sistema, o eleitor tem a possibilidade de votar em um candidato qualquer ou na legenda partidária, sendo que no caso da legenda, os votos dados à sigla de cada partido político são contabilizados apenas para a somatória do quociente partidário, elemento matemático utilizado para calcular o número de cadeiras legislativas conquistadas pelos partidos ou coligações de partidos. Para se promover a distribuição das cadeiras legislativas entre todos os partidos concorrentes pode se adotar como critério tanto o quociente eleitoral, quando a divisão sucessiva (CINTRA, 2006, p. 130-131).

Os defensores deste modelo o apontam como sendo um dos mais democráticos possíveis, pois entendem que ele aproxima o eleitor do candidato, argumentando que na sua dinâmica se produz a necessidade do candidato buscar fortalecer constantemente os seus laços de proximidade com o eleitor. De acordo com Cintra (2006, p. 130):

O parlamento deve ser um mapa acurado das divisões e tendências da sociedade, reproduzindo-as em seus tamanhos relativos. Para seus propugnadores, ele é mais justo, representativo e atende melhor ao imperativo democrático de dar voz às minorias, do que o princípio majoritário (2006, p. 130).

Todavia, a prudente distinguir o sistema majoritário do sistema proporcional. Enquanto o primeiro privilegia a governabilidade, o segundo se apega aos valores políticos da representatividade (KLEIN, 2007, p. 25). Neste caso, se o primeiro se preocupa com a capacidade de governar, não priorizando às demandas por abrangência da representatividade, o segundo, em sentido contrário, se apega prioritariamente a este quesito, colocando em segundo plano a preocupação com a constituição de um "governo forte". No que tange às defesas do voto proporcional em lista aberta, seu maior triunfo é a defesa da fiel obediência à vontade do eleitor.

Entre os fatores que pesam contra este modelo de sistema de voto destacase a corrupção decorrente da disparidade econômica entre os candidatos. Os críticos relacionam que o nível de corrupção se eleva quando o sistema de votos se pauta apenas em candidatos, em personalidades da política. Em regra, eles se tornam reféns de seus eleitores e financiadores de suas campanhas que se 
tornam cada vez mais dispendiosas. A infidelidade partidária é outro entrave apontado pelos críticos do voto proporcional de lista aberta. Argumenta-se que os partidos políticos não possuem força de coerção suficiente sobre os seus integrantes e, no cenário descrito, o "troca troca" de partidos ajuda a desestabilizar o parlamento. Klein, por exemplo, discorda da plenitude desta linha de argumentação e alerta para a continuidade deste problema em caso de adoção do sistema de lista fechada:

Entre 1985 e 2001, 28,8\% dos deputados mudaram de legenda durante o mandato. Esse troca-troca distorce a noção de representação por partidos. A solução, porém, não passa pela alteração do sistema eleitoral. Sistemas de lista fechada também tem a capacidade de incentivar a mudança de sigla, pois um político descontente, cujo nome foi rebaixado ou excluído da lista, pode buscar uma posição melhor na lista de outro partido. (KLEIN, 2007, p. 91).

Para Klein (2007, p. 17), a competição intrapartidária e o individualismo político também são problemas abordados pelos críticos do voto de lista aberta. Alegam que, ao individualizar a campanha, o partido passa a sentir a necessidade de competir internamente por votos, enfraquecendo as suas representações. De modo geral, ao assumir a cadeira no parlamento, o personagem político passa a agir de acordo com as suas perspectivas, deixando de lado o centralismo partidário e a obediência programática. Porém, não há consenso a respeito desta linha de argumentação, sobretudo porque ela é generalizante, não leva em consideração o perfil individual dos partidos políticos inseridos no jogo do poder decisório brasileiro.

Definido isso, a discussão se volta para as propostas partidárias em torno do voto proporcional em lista fechada pré-ordenada e do voto distrital e "distritão". A intenção é descrever as características mais marcantes de cada modalidade de votação, buscando delinear os seus pontos positivos e negativos a partir da visão crítica especializada.

A lista pré-ordenada, apresentada como mecanismo de fortalecimento dos partidos políticos em detrimento do personagem político, é visto por Cristian Klein ( 2007) em sentido de concordância, uma vez que o autor também entende que ele conduz ao fortalecimento da plataforma partidária em detrimento $\mathrm{da}$ escolha de uma personalidade política pelo eleitor. $\mathrm{O}$ fortalecimento da disciplina partidária, em tese, fortalece os interesses programáticos da legenda e beneficia o efetivo combate à corrupção e à infidelidade dos agentes partidários. 
Segundo Klein (2007, p. 18), o mecanismo de fortalecimento do partido se deve às eleições terem os partidos políticos e não os candidatos legislativos como centro das disputas eleitorais. "Com relação ao sistema de lista fechada, entretanto, a menos controvérsia. Os modelos confirmam o consenso na literatura de que esses são os sistemas mais refratários ao cultivo da reputação pessoal e os mais incentivadores da reputação partidária" (KLEIN, 2007, p. 59). Nicolau (2003, p. 219) chama atenção para o fato dos parlamentares que integram o chamado "baixo clero" partidário manifestarem constantemente o desagrado com a possibilidade de ficarem à mercê das elites partidárias, do privilégio oligárquico dos líderes mais destacados nas estruturas dos partidos políticos.

Os defensores da lista fechada também destacam a valorização da disciplina partidária que demarca a identidade dos partidos políticos. Ao tornar o partido a esfera máxima de controle dos parlamentares, as decisões individuais estariam em consonância com as orientações da direção partidária. Se crê na diminuição da corrupção, a acolhida do financiamento exclusivo da campanha somente seria viável em condições de lista fechada, teríamos o fim dos favores aos grandes empresários e outros setores de financiamento de campanhas individuais (KLEIN, 2007, p. 45-69).

Para os críticos, as listas fechadas pré-ordenadas carregam diversos defeitos que justificam a sua não adoção, o principal é a redução do exercício da democracia. Argumentam que ao se retirar a possibilidade do eleitor escolher entre personagens da política, obriga-o a escolher partidos que podem ou não o representar as suas demandas mais específicas, obstruindo as suas possibilidades que se assentam no campos das particularidades que ferem a liberdade democrática de escolha. Seguindo a lógica de poder democrático, com a lista fechada o eleitor perde a prerrogativa de punir os parlamentares que não correspondem às suas aspirações, transferindo aos partidos políticos o poder de aplicar a repreensão (KLEIN, 2007, p. 43-53). Nicolau (2008, p. 135) alerta para a derrocada da accountability personalizada, a ligação direta entre o representante e o representado que danifica a formulação de uma representatividade coesa.

Fernando Limonge discorda que a lista fechada atenua a infidelidade partidária associada aos parlamentares eleitos sob os valores do modelo atual de voto. Para ele, a disciplina no contexto brasileiro já é bastante edificada:

Isso é um mito. Simplesmente não é verdade. Os políticos que estão filiados a um partido votam com o seu partido. De 1989 a 1999 ocorreram 675 votações nominais válidas na câmara 
dos deputados. Nessas votações, a disciplina média do plenário, observando a indicação do líder partidário e como ele votou, é de $91,8 \%$. Ou seja nove em cada dez parlamentares votam com seu partido. Isso significa que o plenário é plenamente previsível, com base na indicação de seus líderes. (LIMONGE, 2003, p. 465)

Cristian Klein também adverte para o mito de que a lista fechada fortalece os partidos políticos, o "ponto que gostaríamos de ressaltar, no entanto, é que a construção de partidos fortes não passa, necessariamente, pela mudança do sistema eleitoral. Partidos são fortalecidos por regras internas, pertinentes à sua própria organização". (KLEIN, 2007, p. 80). Aqui fica claro que para o autor não haveria um incremento no poder partidário somente com a mudança do sistema eleitoral.

Passando para o sistema majoritário, temos que delimitar o que seria o modelo distrital abordado pelos partidos. Trata-se de um sistema que divide o território nacional em distritos eleitorais, espaços geográficos que podem ser de tamanho de unidades federativas, é o caso do distritão, ou de uma região, os chamados distritos, nos quais seriam eleitos os representantes através de maioria relativa ou absoluta de votos (CINTRA, 2006, p. 129).

A prerrogativa central dos defensores do sistema majoritário é a instrumentalização da governança, ou seja, o aprimoramento do processo decisório na instância legislativa. Sob a égide deste modelo, o executivo não encontraria dificuldades $\mathrm{p}$ ara e stabelecer c oalizões. $\mathrm{M}$ esmo q ue o s istema majoritário inclinasse para ao bipartidarismo, seguiria a tendência do partido que encabeça o governo federal manter a maioria no Congresso Nacional (KLEIN, 2007, p. 37). Além do mais, o distrito leva ao parlamento candidatos que possuem interesses vinculados ao espaço geográfico que constrói uma responsabilidade em relação ao seu eleitorado (CINTRA, 2006, p. 129). No mesmo entendimento, Defensor do voto distrital, Nicolau (2003, p. 221) esclarece a sua crítica ao sistema de voto proporcional em lista aberta:

[...] determinadas áreas conseguem eleger seus representantes (políticos que tem como base eleitoral o seu domicilio e outros municípios adjacentes) e outros não; algumas conseguem eleger mais de um parlamentar, enquanto outras são incapazes de fazê-lo. Certos municípios populosos apresentam muitos candidatos, mas a dispersão de votos entre eles faz com que nenhum se eleja. De outro lado, alguns municípios menores que apresentam um único candidato acabam elegendo-o (2003, p. 221). 
Outra linha argumentativa defendida para a adoção desse sistema se encontra no combate à desfragmentação partidária, criando um obstáculo institucional, o voto distrital, para se buscar a concentração em partidos de grande influência, i nibindo a e xistência $\mathrm{d}$ os partidos $\mathrm{d}$ e a luguel e a fins. Também se enfoca a diminuição dos gastos com campanha, visto que com o espaço geográfico reduzido não haveria necessidade do emprego de grandes quantidades de recursos nas campanhas eleitorais (LAGO; RAMOS, 2012, p. 719-722).

Entretanto, tais afirmativas n ão e ncontram $r$ espaldos e nergéticos q ue consigam se sustentar. Algumas falhas pontuais podem colocar em risco a própria noção de democracia, como apontam Lago e Ramos (2012, p. 723):

Pessoas que vivem nos mesmos espaços têm desejos, expectativas e demandas distintas, ao passo que outras separadas por longas distâncias físicas possuem grande proximidade e afinidade no que diz respeito à opiniões, ideias e projetos de sociedade. Portanto, ao traduzirem tais “visões de mundo" em opções políticas, por exemplo, na hora de escolherem um representante, os eleitores precisam de opções que lhes assegurem a defesa dessas concepções, que lhes são características, acerca da realidade, não a representação de espaços geográficos que já não mais servem como fator de construção de identidades.

Sob este enfoque se coloca em cheque o argumento de que os distritos produziriam benefícios ao sistema eleitoral por representarem regiões diminutas. Em particular, esse modelo desfavorece as minorias políticas que somente alcançaram a participação legislativa em função do sistema proporcional de voto. Com o voto distrital, minorias representativas dos negros, indígenas, ambientalistas, GLBTs e evangélicos, por exemplo, teriam maiores dificuldades para se fazerem representar legislativamente. Vale destacar, que em regra, são esses setores minoritários de nossa sociedade que mais demandam atuar no universo da produção de um sistema legal que ainda os negligencia (LAGO; RAMOS, 2012, p.724-725).

No que tange a diminuição de custos das campanhas eleitorais em um sistema distrital, ainda não há pesquisas que comprovem tal lógica argumentativa. A grosso modo, é possível acreditar que quanto mais acirrada fica a disputa em um determinado distrito, maior será a demanda de materiais e ações destinadas a sanar o lapso de votos pendentes, gerando gastos de campanha cada vez maiores. 
Em primeiro lugar trata-se, mais uma vez, de algo hipotético. Não existe qualquer estudo que demonstre, por exemplo, relação positiva entre o montante de recursos gastos pelos candidatos e o espaço ao qual ele direciona sua campanha. Ou seja, não há como dizer, por exemplo, que os deputados gastam mais à medida que dispersam geograficamente suas campanhas durante $\mathrm{O}$ período eleitoral (RAMOS; LEMOS, 2012, p. 374-375).

Sobre o voto distrital misto, apontado por muitos como a proposta mais razoável para a reforma política brasileira, por entenderem que ele contempla os mais diversos interesses no âmbito legislativo. Klein (2007, p. 18) destaca que esse modelo congrega o que há de melhor nos modelos majoritário e proporcional, relativizando os pontos negativos que atrapalham a adoção de apenas um deles. Prevalece aqui a ideia de que unindo ambos os modelos poderíamos alcançar a satisfação tanto no campo parlamentar, quanto no social.

O sistema funcionaria a partir de dois votos, um majoritário para se eleger um personagem político lotado no distrito e outro partidário para atender a necessidade de eleição de um representante no contexto eleitoral geral. Enzweiler (2008, p. 129) alerta para os posicionamentos críticos à adoção do modelo distrital misto de voto, que apontam deficiências na proporcionalidade adotada e no critério majoritário, enfim, o bservando que este m odelo não absorve apenas o que há de melhor nos dois modelos originais, incorpora o que há de mais negativo também.

\section{CONSIDERAC̣ÕES FINAIS}

A reforma política expressa um combate perpétuo entre forças políticas e sociais. Ela envolve interesses que ultrapassam o quadro representativo e adentra em todos os cantos do nosso país. Sua imprudência pode provocar problemas institucionais de dimensões ultra danosas, suplantando liberdades conquistadas duramente conquistadas ao longo dos anos. Entretanto, não existe um sistema político perfeito e muito menos fórmulas que satisfaçam as demandas de todos os setores da sociedade nacional. Conforme salienta Klein (2007, p. 27), não "é possível determinar que um método seja melhor que o outro. Não há sistema eleitoral perfeito, e sim mais ou menos adequados a princípios que se querem ou se devem atender."

Os efeitos esperados quase sempre se chocam com os efeitos concretos, afinal, 
é impossível que eles impactem positivamente o todo de maneira homogênea e harmônica. Não há conciliação entre os integrantes da sociedade civil e muito menos das estruturas institucionais que se cruzam para concretizar as reformas em debate (CINTRA, 2006, p. 128). Contemporânea da Constituição de 1988, a bandeira da reforma política não pode ser tomada apenas pelas estruturas formais do processo democrático. O povo, dotado de liberdade e vontade deve se abastecer de informações sobre o tema e participar ativamente do processo de reforma política em curso.

Não é tarefa simples apontar qual seria o melhor sistema eleitoral para se adotar atualmente no Brasil. É evidente que há problemas explícitos que precisam ser corrigidos, mas não podemos ignorar os ganhos de alguns mecanismos que nos permitem, hoje, gozar de uma das maiores democracias do mundo. É importante frisar que a constante manutenção da democracia gera a própria reprodução do seu fortalecimento, isso por si só, deveria ser o parâmetro da reforma política em todas as suas esferas.

De todo modo, não é possível singularizar a análise da reforma política. Nosso sistema político é todo interligado e não são mudanças esporádicas que suprirão as deficiências sistêmicas que todos nós observamos diariamente.

Sendo assim, essa pesquisa se restringe a levantar algumas opções dadas pelos partidos políticos no campo do sistema de exercício do voto e acompanhálas no seu aspecto argumentativo. Essa disputa que se dá no campo das ideias e dos interesses não envolve um espectro político específico. Não há uma divisão que envolva propostas nos campos da direita e da esquerda partidária, situação essa que pode abrir caminho à uma condição favorável de debate sobre os diversos pontos e temas que envolvem a reforma do sistema político no Brasil. 


\section{Title: The Vote in front of the Political Reform: Party proposals for a new Brazilian electoral scene.}

\section{Abstract}

The 2014 elections were guided by proposals that didn't match the popular will until June 2013, proposals these which headed by an unique desire to reform not just some points of the political model, but all of it. In order to take the concerns and conflicts of civil society at all levels of the political institutions of state power, the political party becomes indispensable for the exercise of representative democracy institution. In the scenario where parties come and go every election, we have both: historical parties, ideologically and programmatically solidified, as the famous rental subtitles, that lead to bargaining and issues that vulgarize the power play and party identity. Presently, the reform of the Brazilian political system is one of the most debated topics in the intellectualized political circles, and in several organized groups of our society. The political parties are central institutions in the course of political reform which apparently became inevitable. In this manner, the electoral rules should be modified with this new political paradigm, such as the maximum and sovereign institution of popular expression, voting. The discussion of electoral models is the goal of this work, not aiming to establish a "perfect" way in the various studied. Basing on national academic output on the subject, discussing favorable and negative points, this article will examine the proposals for reform of the voting system in Brazil with reference to the most relevant political parties in our current game-making decisions.

Keywords: Political Reform; Political Parties; Vote. 


\section{REFERÊNCIAS}

AVRITZER, Leonardo; ANASTASIA, Fátima. Reforma política no Brasil. Belo Horizonte: Editora UFMG, 2006.

BENEVIDES, Maria Victória de Mesquita; VANNUCHI, Paulo; COMPARATO, Fábio Konder. Reforma política e cidadania. São Paulo: Editora Fundação Perseu Abramo, 2003.

CINTRA, Antonio Octavio. Sistema Eleitoral. In: Leonardo Avritzer; Fátima Anastasia (Org.). Reforma Política no Brasil. 1 ed. Belo Horizonte: UFMG, 2006.

. Reforma Política: mudando os termos da Conexão Eleitoral. In: Timothy Mulholland; Lúcio

R. Rennó (Org.). Reforma Política em Questão. 1 ed. Braślia: UnB, 2008.

ENZWELLER, Romano José. Dimensões do sistema eleitoral: 0 distrital misto no Brasil. Florianópolis: Conceito Editorial, 2008.

LAGO, Ivann Carlos; RAMOS, Flávio. 0 Voto Distrital no Contexto da Reforma Política: implicações na institucionalidade democrática e no princípio da representação. Recife: Revista Política Hoje, v. 20, n. 2, 2012.

LIMONGI, Fernando. Mesa voto distrital, voto proporcional e coligações. In: Maria Victória Benevides, Paulo Vanuchi e Fábio Konder (Org.). Reforma Política e Cidadania. São Paulo: Editora Fundação Perseu Abramo, 2003. P. 462 a p. 466 ..

NICOLAU, Jairo. Lista Aberta, Lista Fechada. In: Leonardo Avritzer e Fátima Anastasia. (Org.). Reforma Política no Brasil. 1 ed. Belo Horizonte: Editora UFMG, 2006.

A Reforma da Representação Proporcional no Brasil. In: Maria Victória Benevides; Paulo Vannuchi; Fábio Konder (Org.). Reforma Política e Cidadania. São Paulo: Fundação Perseu Abramo, 2003. P. 201 a p.224. 